\title{
EMILY DICKINSON E A POESIA DE AUTORIA FEMININA
}

\section{EMILY DICKINSON AND THE POETRY OF FEMALE AUTHORSHIP}

\author{
Alcides Cardoso dos SANTOS ${ }^{3}$
}

\begin{abstract}
RESUMO: Faremos uma leitura do poema 754 de Emily Dickinson, "My Life had stood - a Loaded Gun", à luz da teoria feminista de Sandra Gilbert e Suzan Gubar com o intuito de entender o dilema da autoria feminina no século XIX: a necessidade de auto-afirmação poética em contraposição à impossibilidade de auto-afirmação como mulher em uma sociedade patriarcal. O poema 754 dramatiza esse dilema criando uma cena pastoril na qual é a personagem feminina que fala e age em nome do homem, invertendo os papéis do gênero pastoril e da sociedade norte-americana da época. Esta inversão é que possibilita a superação do dilema, na medida em que pressupõe um eu-lírico de voz forte e eloquente, capaz de se pronunciar afirmativamente sobre assuntos do universo masculino enquanto silencia a voz masculina.
\end{abstract}

PALAVRAS-CHAVE: Poesia norte-americana; Dickinson; Crítica feminista; Autoria feminina.

ABSTRACT: In this work we shall analyze Emily Dickinson's "My Life had stood - a Loaded Gun" (Poem 754) through Sandra Gilbert and Suzan Gubar's feminist poetic theory with the aim of understanding the dilemma of female authorship in XIX century North-American poetry: the need for poetical self-assertion in contrast to the personal self-denial of a woman in a patriarchal society. Poem 754 dramatizes such dilemma in a pastoral scene in which the female character speaks and acts on behalf of the man, inverting the roles of the pastoral genre as well as of Dickinson's contemporary North American society. It is such inversion of roles the

\footnotetext{
${ }^{3}$ Departamento de Letras Modernas. Programa de Pós-Graduação em Estudos Literários - Faculdade de Ciências e Letras - Universidade Estadual Paulista (UNESP), campus de Araraquara - CEP 14800-901 Araraquara - SP - Brasil - E-mail: alcides@fclar.unesp.br
} 
enables the female poet to overcome the dilemma by creating a lyrical self empowered by a strong and eloquent voice who is able to speak up affirmatively upon man's affairs while silencing his voice.

KEYWORDS: North American poetry; Dickinson; Feminist criticism; Female authorship.

A evolução de um artista é um contínuo auto-sacrifício, uma contínua extinção da personalidade.

T. S. Eliot

O drama da mulher é esse conflito entre a reivindicação fundamental de todo sujeito que se põe sempre como o essencial e as exigências de uma situação que a constitui como inessencial. Simone de Beauvoir

Gostaria de, no curto espaço deste texto, levantar e discutir uma questão que creio ser de fundamental importância no estudo da poesia: a autoria feminina tem alguma relevância para o estudo da poesia lírica? Se a resposta for positiva, como acredito que será, gostaria de entabular sequência a ela: qual é a importância da autoria feminina da poesia lírica? Vou tentar indicar alguns possíveis encaminhamentos para esta discussão a partir do caso de Emily Dickinson (1830-1886), uma das poetas cuja obra faz confluir poesia e biografia num jogo de personas cujo alcance embaralha as distinções mais tradicionais de vida e obra, feito singular na história da poesia e que permitiu à poeta criar uma voz lírica forte o bastante para administrar poeticamente os impulsos de auto-afirmação poética e o de auto-negação pessoal. Partimos do pressuposto de que este conflito é inerente à poesia de autoria feminina e de que as soluções encontradas pelas poetas de diferentes épocas podem ser pensadas conjuntamente como uma "poética feminista", como o fazem Gubar e Gilbert (2000). 
Esta conjugação dupla de impulsos contraditórios criou uma complexidade na poesia de Dickinson que culminou, até muito recentemente, em avaliações nem tanto meritórias, como afirma Camile Paglia no capítulo dedicado a Emily Dickinson em Personas sexuais (1990, p.571-572):

\begin{abstract}
Nenhuma grande figura na história literária tem sido mais malentendida. Ignorada por sua própria época, Emily foi sentimentalizada em sua renascença. Após trinta anos de estudos, reconhece-se universalmente a complexidade modernista de seu alto estilo. Mas a crítica ainda ignora o grosso da lírica sentimental em suas obras completas. Não há integração de seus alto e baixo estilos.
\end{abstract}

Longe de querer reanimar teorias novecentistas do autor, concordamos com Simone de Beauvoir quando esta afirma, na introdução a $O$ segundo sexo, que "A humanidade é masculina e o homem define a mulher não em si, mas relativamente a ele; ela não é considerada um ser autônomo" (1970, p.10) e reclama que as mulheres "não se põem autenticamente como Sujeito" (p.13). Assim como fez a própria Simone de Beauvoir, cremos que ao assumir a escrita, sobretudo a literária e principalmente a poética, a autora se coloca como sujeito de sua própria história e, por conseguinte, assume um papel ativo que contradiz a passividade a que a mulher foi relegada historicamente, isto é, a mulher, ao se tornar poeta, ajuda a construir uma tradição feminina na literatura, pois “Todos podemos unir-nos nessa devota esperança, mas é duvidoso que a poesia possa emergir de uma incubadeira. A poesia precisa ter uma mãe e também um pai" (WOOLF, s/d, p.126; grifos meus), como bem lembra Virginia Woolf em Um teto todo seu, texto escrito em 1928.

Como afirma Harold Bloom em A angústia da influência (1991), o poeta tem um pai literário como principal antagonista de sua auto-afirmação poética e uma longa tradição que autoriza a sua voz poética, ou seja, o efebo está autorizado a lutar por um espaço no panteão dos grandes poetas pelo simples fato de sua pertença ao gênero masculino, pois o elo que fundamenta toda tradição, a philía, só se estabelece entre sujeitos, como afirma Jacques Derrida em The politics of friendship (2005, p.10). Não podendo historicamente se colocar como sujeitos e não tendo podido construir uma 
tradição feminina na literatura até o século $\mathrm{XX}$, as poetas não tiveram nem mães literárias para indicar o caminho e nem uma tradição feminina como referência, o que faz da autoria feminina, na definição de Gubar e Gilbert, não mais uma "angústia da influência", mas uma "angústia da autoria", na qual a poeta experimenta "um medo radical de que ela não possa criar, de que pelo fato de ela nunca poder se tornar um 'precursor', o ato de escrever causará seu isolamento ou destruição" (2000, p.49; tradução minha).

Discuto, aqui, especificamente a autoria de poesia no século XIX, uma vez que o romance parece ter sido, ainda nas palavras de Gubar e Gilbert, uma invenção feminina novecentista, pois “...tanto a história da literatura inglesa quanto a norte-americana registram as realizações de numerosas e distintas de prosistas - ensaístas, diaristas, jornalistas, missivistas e (especialmente) romancistas" (GUBAR e GILBERT, 2000, p.542), realizações estas que inclusive garantiram o sustento material de muitas delas, como nos diz Virginia Woolf (WOOLF, s/d, p.81):

O marido poderia morrer, ou alguma desgraça atingir-lhe a família. Centenas de mulheres começaram, no decorrer do século XVIII, a contribuir para o provimento das despesas pessoais ou ir em socorro da família, fazendo traduções ou escrevendo os inúmeros romances de má qualidade que deixaram de ser registrados até mesmo nos compêndios, mas que podem ser obtidos nas caixas de quatro pence na Charing Cross Road.

Porém, o caminho das mulheres em direção à autoria da poesia foi - e por que não dizer tem sido até bem recentemente - bastante mais difícil, pois sem ter uma linhagem de poetas mulheres para dar continuidade, as poetas tiveram que partir da tradição poética estabelecida como referência para sua criação e para fazê-lo tiveram que se integrar à tradição do poeta demiurgo, aquele que escreve "[...] o que os poetas masculinos escrevem - isto é, sobre Deus, o destino, o tempo e a integridade...”, o que teria sido, pelo menos até meados do século $\mathrm{XX}$, senão um absurdo, pelo menos algo risível, pois o senso comum dizia que "[...] a arte de uma mulher poeta deve, em algum sentido, surgir de sentimentos 'românticos' (no sentido popular e sentimental), deve 
surgir ou como resposta a um romance real ou como uma compensação por um romance não vivido.” (GUBAR e GILBERT, 2000, p.542/543; tradução minha).

A criação poética, no caso das poetas mulheres ${ }^{4}$, sofre, então, a dupla injunção da ausência de uma tradição feminina e de uma negação do acesso aos temas "sérios", resultando na já conhecida proximidade da literatura de autoria feminina (sobretudo a produção em prosa) com o tema da domesticidade, como podemos perceber nos romances da Jane Austen, das irmãs Brönte e mesmo de Virginia Woolf. É claro que a aceitação da domesticidade como tema "feminino" não acontecerá sem que esta escrita feminina seja permeada por um subtexto subversivo e até mesmo irônico das regras e convenções criadas pelos homens, principalmente das imagens de anjo e monstro criadas para representar/aprisionar as mulheres em estereótipos fixos. Como dizem Gubar e Gilbert (2000, p.73; tradução e ênfase minhas),

[...] as mulheres, de Jane Austen e Mary Shelley a Emily Brönte e Emily Dickinson produziram obras literárias que são de alguma forma palimpsestos, obras cujo conteúdo superficial esconde ou obscurece camadas de sentido mais profundas e menos acessíveis (e menos aceitas socialmente). Portanto, estas autoras conseguiram a dupla tarefa de obter uma autoridade literária feminina real simultaneamente se conformando e subvertendo os padrões literários patriarcais.

Se na prosa as autoras novecentistas conseguiram o duplo feito de aceitar e subverter a tradição patriarcal por meio da escrita em palimpsesto, no caso da poesia lírica, este gênero literário que na tradição poética é visto como "inerentemente incompatível com a natureza ou essência da feminilidade" (GUBAR e GILBERT, 2000, p.541), esta dificuldade aumentava exponencialmente, pois “A indiferença do mundo, que Keats e Flaubert e outros homens de gênio tiveram tanta dificuldade de suportar, não era, no caso da mulher, indiferença, mas sim hostilidade.“ (WOOLF, s/d, p.66) A loucura platônica que permitia ao poeta transcender a existência e se tornar, ao mesmo

\footnotetext{
${ }^{4}$ Insistirei na marcação do gênero além do artigo definido para enfatizar o tema aqui discutido. Desta forma, me referirei às autoras de poesia como "Poetas mulheres".
} 
tempo, um ser divino e diabólico, nas poetas mulheres era considerado como sandice ou, nos casos mais graves, insanidade: "Agitar o punho prometeico masculino "contra Deus' é uma estratégia poética perfeitamente razoável, aparentemente, mas bater o 'minúsculo' pé feminino é outra completamente diferente" (GUBAR e GILBERT, 2000, p.542).

Como bem apontam Gubar e Gilbert (2000), a prosa de ficção permitia às autoras transferir para seus personagens as tensões da autoria feminina em uma sociedade patriarcal por meio da criação de uma variedade de personagens femininos que abrangem desde os extremos do "anjo do lar" à "queenly woman", como dizia Virginia Woolf, o que não acontecia na poesia, pois

[...] enquanto a mulher romancista pode evadir ou exorcizar suas angústias da autoria escrevendo sobre loucas e outros duplos demoníacos, parece que a mulher poeta deve literalmente tornar-se uma louca, interpretar o papel diabólico e se prostrar dramaticamente morta na encruzilhada da tradição e gênero, sociedade e arte. (GUBAR e GILBERT, 2000, p.545).

O eu-lírico, cuja visão de mundo o poema transparece, está irremediavelmente constrito ao mundo que o cerca e suas complexidades, o que não significa dizer que será um reflexo deste. Pelo contrário, o que nos interessa, no caso da autoria poética feminina, é deslindar algumas estratégias poéticas que permitiram às poetas habitar poeticamente a tradição eminentemente masculina, pois cremos, com Heidegger (1971), que entre a existência histórica do poeta e a voz lírica em ação há a poesia, que a ambos cria e que abre a clareira do ser para existência histórica da humanidade tanto quanto da poesia. Se o eu-lírico, na tradição poética, é revestido de autoridade para falar sobre Deus, o mundo e os homens e sua voz é portadora de autoridade e força - como o eulírico whitmaniano que, a plenos pulmões bradava, em Folhas de relva, "I speak the password primeval, I give the sign of democracy" - o eu-lírico feminino manifesta um dos sinais mais visíveis da exclusão da autoria poética feminina diante da tradição, que é o apequenamento do eu-lírico, como vemos neste poema em que Emily Dickinson parece se dirigir a uma leitora mais que a um leitor: "Não sou Ninguém! Quem é você? / 
Ninguém — Também? / Então somos um par? / Não conte! Podem espalhar!" (poema 288 na tradução de Augusto de Campos) (DICKINSON, 1986, p.116-117).

Outro exemplo eloquente do apequenamento do eu-lírico pode ser visto nos versos iniciais do prólogo de The tenth muse, a principal obra da primeira poeta norteamericana, a seiscentista Anne Breadstreet (apud BRADLEY, 1974, p.22):

\author{
To sing of wars, of captains, and of kings, \\ Of cities founded, commonwealths begun, \\ For my mean pen are too superior things; \\ Or how they all, or each, their dates have run; \\ Let poets and historians set these forth; \\ My obscure lines shall not dim their worth.
}

Outro exemplo, dos inúmeros que poderíamos citar para ilustrar a estratégia poética do apequenamento da voz lírica feminina, são estes versos do poema "Grande desejo", da poeta mineira Adélia Prado em seu livro de estréia Bagagem, de 1976 (PRADO, 2007, p.10):

Não sou matrona, mãe dos Gracos, Cornélia,

Sou é mulher do povo, mãe de filhos, Adélia.

Faço comida e como.

Aos domingos bato o osso no prato pra chamar o cachorro

E atiro os restos.

Quando dói, grito ai,

Quando é bom, fico bruta,

As sensibilidades sem governo. 
Porém, o apequenamento da voz lírica feminina geralmente traz consigo um subtexto irônico, um palimpsesto, no qual a voz poética masculina é esvaziada de sua autoridade, potencializando a linguagem do poema com a tensão entre a autonegação pessoal e a auto-afirmação poética da voz lírica feminina, entre a existência histórica da poeta e sua existência poética na forma de um sujeito lírico, elo que a tradição poética modernista, sobretudo a de extração anglo-saxônica, buscou apagar, como foi lembrado por meio da epígrafe a este texto, retirada do famoso ensaio de T. S. Eliot, "Tradição e talento individual" (1989, p.42). Tal subtexto irônico permite à poeta o duplo movimento de acatar e tornar risível uma tradição fortemente alicerçada no platonismo tanto quanto no cristianismo, como explica Simone de Beauvoir (1970, p.16): "Mas os homens não podiam gozar plenamente este privilégio [de serem homens], se não o houvessem considerado alicerçado no absoluto e na eternidade: de sua supremacia procuraram fazer um direito."

O subtexto irônico na poesia de autoria feminina - que se associa ao prazer feminino, que as feministas denominaram, no esteio de Jacques Lacan, jouissance produzirá o efeito de corroer sutilmente a autoridade de uma voz poética alicerçada na tradição por meio da sutileza mais do que pelo enfrentamento aberto. Vejamos como a estrofe 5 do prólogo de The tenth muse evolui do apequenamento do sujeito lírico feminino nos primeiros versos para a derrisão da voz lírica masculina (apud BRADLEY, 1974, p.23):

\section{I am obnoxious to each carping tongue}

Who says my hand a needle better fits;

A poet's pen all scorn I should thus wrong,

For such despite they cast on female wits.

If what I do prove well, it won't advance;

They'll say it was stol'n, or it was by chance. 
Também encontraremos este movimento de derrisão da tradição masculina na poesia de Adélia Prado, como vemos nos versos finais do poema "Com licença poética”, em que a poeta mineira faz clara alusão à tradição modernista brasileira: "Minha tristeza não tem pedigree, / já a minha vontade de alegria, / sua raiz vai ao meu mil avô. / Vai ser coxo na vida é maldição pra homem. / Mulher é desdobrável. Eu sou." (PRADO, 2007, p.9).

O apequenamento do eu-lírico como estratégia poética é, na verdade, uma manifestação da dupla injunção da autoria poética feminina, a necessidade de autoafirmação poética contraposta à impossibilidade de auto-afirmação pessoal, que pode ser percebida no poema pelos vetores complementares de aceitação e derrisão da tradição e da voz poética eminentemente masculinas. Podem ser uma importante chave de leitura da poesia de Emily Dickinson e, por extensão, da poesia de autoria feminina. Leiamos o poema 754, "My Life had stood - a Loaded Gun" por meio da dupla injunção da poesia de autoria feminina que, acreditamos, pode se uma importante chave na leitura da poesia de Emily Dickinson. Apresentamos o poema no original e em sua tradução feita por Ana Luisa Amaral (disponível em:

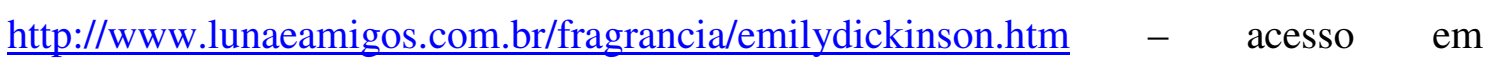
25/07/2010):

My Life had stood - a Loaded Gun -

In Corners - till a Day

The Owner passed - identified -

And carried Me away -

And now We roam in Sovereign Woods -

And now We hunt the Doe -

And every time I speak for Him -

The Mountains straight reply -

And do I smile, such cordial light

Upon the Valley glow -

It is as a Vesuvian face

Had let its pleasure through -

And when at Night - Our good Day done -

I guard My Master's Head -

'Tis better than the Eider-Duck's

Deep Pillow - to have shared - 
To foe of His - I'm deadly foe -

None stir the second time -

On whom I lay a Yellow Eye -

Or an emphatic Thumb -

Though I than He - may longer live

He longer must - than I -

For I have but the power to kill,

Without--the power to die--

Espingarda Carregada - a minha Vida -

Por Cantos - assim for a

Até passar o Dono - Me marcar -

E Me levar embora -

E agora erramos em Bosques Reais -

E perseguimos uma Corça agora -

E cada vez que falo em Sua vez -

As Montanhas respondem sem demora -

E se eu sorrio, uma amigável luz -

No Vale se faz ver -

É como se uma face de Vesúvio

Soltasse o seu prazer

E quando à Noite - já cumprido o Dia -

Guardo a Cabeça do Meu Dono -

Melhor do que Almofada em Penas Suaves

Partilhada - no sono -

Do inimigo Seu - sou-o, mortal -

Não se torna a agitar -

Esse em quem pouse o meu Olho Amarelo -

Ou enfático Polegar -

Embora eu possa viver mais - do que Ele 
Ele mais do que eu - deve viver -

Que eu só tenho o poder de matar,

Sem - o poder de morrer -

O poema reproduz uma cena pastoril, com os seus elementos temáticos claramente estabelecidos: a natureza ("Woods", "Mountains", "Valley"), a caçada ("Gun", "Doe”), a alternância bem marcada do dia ("Day", "hunt", "Light" e todos os verbos de atividade tanto no passado recente, "passed", "identified", "carried", como os de atividade regular, "roam", "hunt", "speak", "reply", "smile”, "guard", "stir", "lay”) e da noite ("Night", "pillow"), isto é, o poema se perfila à tradição do poema pastoril, na qual a harmonia entre o homem e a natureza deu a tônica através dos séculos.

O eu-lírico que toma a posição de sujeito do poema se coloca claramente como sujeito feminino, cuja vida é, a princípio, inativa ("My Life had stood"), até que um dia é visitada por um personagem que traz características claramente masculinas de ação e poder de decisão, pois ele passa ("passed"), identifica-a como mulher ("identified") e toma posse dela, carregando-a consigo ("Carried me Away"), ou seja, o eu-lírico, a princípio, é uma mulher como todas as outras, passível de identificação e apropriação por um sujeito masculino que, por sua vez, é identificado pelo eu-lírico como tal ("The Owner”, "My Master”).

A cena pastoril se conforma à tradição do poema pastoril até os dois primeiros versos da segunda estrofe, nos quais o casal passeia pelos bosques reais e caça, ainda em sugestão de que a atividade é liderada pelo sujeito masculino, mesmo que na companhia do eu-lírico feminino.

Porém, já no terceiro verso da segunda estrofe há a primeira inversão dos papéis tradicionais de agente e paciente, isto é, o homem, que é o agente das primeiras ações de passar, identificar e carregar, se torna paulatinamente paciente das ações do eu-lírico feminino, ao passo que este, de sua posição inicial de inatividade e passividade, se torna

\footnotetext{
${ }^{5}$ Farei referência ao poema em sua versão original, pois os vocábulos em inglês guardam um poder de sugestão maior do que a tradução em português.
} 
primeiramente o portador da voz ("every time I speak for Him") e, depois, agente da ação em praticamente todo o poema, fato que também é refletido pela mudança dos tempos verbais de passado simples (primeira estrofe - inatividade/passividade) para presente simples (atividade conjunta com o personagem masculino: "And now We roam in Sovereign woods / And now We hunt the Doe").

Como uma resposta poética ao silenciamento histórico e literário das mulheres ao longo de séculos, a voz lírica silencia o personagem masculino que, exceto pelas ações iniciais, não tem mais capacidade de voz ou ação, pois é o sujeito lírico feminino que fala e age por ele. Entretanto, é interessante notar que o eu-lírico feminino quando fala não se dirige a ele, mas ao leitor, e toda vez que o faz recebe a resposta positiva da natureza, em primeiro lugar da montanha ("The Mountains straight reply") e, posteriormente, do Vale ("such cordial light / Upon the Valley glow"), como a reafirmar a antiga associação feita pelo imaginário masculino literário da mulher com a natureza/terra. Neste momento a sintaxe do poema também reflete esta mudança de posição do eu-lírico, com a mudança dos verbos do passado para o presente, acrescidos do advérbio de tempo "Now", enfatizando o momento presente da mudança no poema, momento este que será definitivo para a consciência do sujeito lírico feminino a partir deste momento.

$\mathrm{Na}$ tradição de representação da mulher na literatura, sua associação com a natureza foi simbolizada por meio da maternidade, da capacidade de gerar filhos que a assemelha à força gerativa da natureza e dá origem ao conceito de Mãe-Terra, um conceito que idealiza a mulher na pureza assexuada da maternidade - da qual a representação cristã da Virgem Maria é o paradigma - ao mesmo tempo em que a aprisiona nesta idealização ao separar a geração biológica da fisiológica, pois as mulheres "[...] não conseguem transcender suas limitações físicas femininas: elas não podem conceber a si próprias em qualquer outro sentido que não o reprodutivo" (GUBAR e GILBERT, 2000, p.32). A separação da geração biológica da geração cultural estabelece que as mulheres têm o "dom" e, portanto, a obrigação de gerarem filhos, mas a forma de geração infinitamente mais relevante é a cultural, que só pode ser exercida por sujeitos, isto é, por homens. Desta forma, a paternidade foi elevada a uma condição superior à maternidade, pelo fato de o pai também ser um pai biológico, mas 
sobretudo pelo fato de ser um pai cultural. Assim, um texto só pode ter um pai, um pater que garantirá a continuidade da cultura por meio do seu instrumento gerativo, a pena/pênis, pois

Na cultura patriarcal ocidental, portanto, o autor de um texto é um pai, um progenitor, um procriador, um patriarca estético cuja pena é um instrumento de poder gerativo como seu pênis. (GUBAR e GILBERT, 2000, p.6; tradução minha).

A verdadeira força gerativa, aquela que a tradição associou à paternidade, sofre, no poema, uma mudança de agente a partir da segunda estrofe, quando o eu-lírico feminino fala em nome do personagem masculino e tem a resposta afirmativa dos elementos da natureza (Montanhas e Vale). Esta resposta, ao invés de confirmar o esperado, i. e., a associação idílica da mulher com a harmonia da natureza, terá o efeito contrário de incitar uma certa força e um certo poder femininos que pareciam adormecidos, culminando em um clímax em que o despertar feminino desencadeado pela resposta da natureza é comparado a um vulcão em erupção ("It is as a Vesuvian face”). Como a força ctônica que Camille Paglia associa ao princípio feminino (1990), o poema atinge, neste dístico que é sua metade exata, seu clímax, com a erupção orgasmática do eu-lírico feminino que libera seu prazer ("Had let its pleasure through"), disparando assim a sua arma carregada de séculos de repressão e silenciamento da voz feminina.

Neste ponto central de mudança no poema parece haver uma transformação que julgamos ser radical em nossa percepção de como a poesia de Emily Dickinson soluciona poeticamente a dupla injunção da autoria poética feminina. O eu-lírico do poema em questão, em sua Bildung de consciência da poeta mulher na sociedade patriarcal, adquire o conhecimento de si e do mundo durante o poema, pois passa de um estado de inércia/passividade (o primeiro dístico) para um estado em que sofre a atividade de um agente masculino (versos 3 a 6), que resulta em um estado de atividade, no qual o eu-lírico fala e age pelo personagem masculino (versos 7 a 10). Neste ponto do poema, a identificação do sujeito lírico com um vulcão em erupção libera uma 
vontade de potência nietzscheana no eu-lírico feminino, levando-o a uma posição não de porta-voz, mas de voz única e afirmativa, protegendo o personagem masculino como se este não pudesse/soubesse mais falar por si próprio ou se proteger.

O sujeito lírico, então, assume totalmente a ação e após o término do dia, chama a si a função de proteger os seus (“And when at Night - Our good Day done - / I guard My Master's Head"), função esta que lhe dá mais prazer do que simplesmente compartilhar o leito de seu senhor (“'Tis better than the Eider-Duck's / Deep Pillow - to have shared"), uma vez que sua função é ativa, e não mais passiva. A atividade de que agora o eu-lírico feminino é agente lhe traz prazer a tal ponto que esta atividade evolui para uma verdadeira hostilidade e agressividade para todos os que porventura queiram mal ao seu senhor/dono, despertando neste eu-lírico uma atitude que poderia ser descrita como beligerante ("To foe of His - I'm deadly foe - / None stir the second time"), cujo poder não vem da uma arma branca ou de fogo - apesar do título, a arma carregada é uma metáfora para a vida do sujeito lírico até o momento em que a "ação" em sua vida acontece, mas não é, em momento algum, metaforizada como instrumento letal -, mas de seu próprio corpo ("On whom I lay a Yellow Eye - / Or an emphatic Thumb”), reforçando a asserção das feministas francesas de que a experiência feminina do mundo não pode ser dissociada do corpo, apesar de a tradição ocidental filosófica e religiosa partir do pressuposto da separação entre corpo e mente. $\mathrm{O}$ ocidente criado pelos homens traz a marca da dualidade corpo/mente, ao passo que a experiência de mundo da mulher só pode se dar pela "via crucis do corpo", para lembrar Clarice Lispector. Como diz Hélène Cixous em Sorties (2001, p.94; tradução minha):

Nós nos afastamos de nossos corpos. Envergonhadamente aprendemos a não prestar atenção a eles, a açoitá-los com estúpida modéstia; fomos enganadas em uma barganha de tolo: cada um deve amar o outro sexo. Eu te darei o seu corpo e você me dará o meu. Mas quais homens dão às mulheres o corpo que elas cegamente entregam a eles? Por que tão poucos textos? Porque ainda há tão poucas mulheres resgatando seus corpos.

"Resgatar" o corpo pela via da escrita parece, então, ser um dos caminhos que as mulheres têm adotado ao longo de séculos de silenciamento e dominação, processo este 
que, como vimos, é complexo e envolve um subtexto irônico que, a uma leitura consciente das questões de gênero, demonstra uma clara consciência das escritoras a respeito da dificuldade de uma mulher em ser uma autora. Pode-se dizer que tal resgate acontece na medida em que o poema acontece e o eu-lírico assume sua posição de sujeito da história, como queria Simone de Beauvoir, isto é, à medida que o poema se desenvolve e o sujeito lírico se constrói e adquire uma consciência crescente de sua "posição no universo como um ser humano", como escreveu Kate Chopin ${ }^{6}$ a respeito da protagonista de seu principal romance, $O$ despertar (1993, p.13; tradução minha):

Em resumo, a Sra. Pontellier estava começando a compreender a sua posição no universo como um ser humano e a reconhecer as suas relações como um indivíduo com o mundo dentro e ao seu redor. Isto pode parecer um peso exagerado de sabedoria a descender sobre a alma de uma jovem mulher de vinte e oito anos - talvez mais sabedoria que normalmente agradaria ao Espírito Santo conceder a qualquer mulher.

Esta consciência, este "despertar" da consciência feminina, teve seus momentos importantes na história nas ocasiões em que as mulheres perceberam que o letramento e a educação eram os esteios fundamentais da sociedade burguesa, como o fizeram Mary Woolstonecraft e as Bluestockings inglesas, Simone de Beauvoir, Virginia Woolf e todas as escritoras que ajudaram a construir uma tradição feminina de reflexão literária ou não - sobre a questão de gênero. Mas foi na literatura, ou, melhor dizendo, na utilização do espaço literário para a discussão de temas importantes para as mulheres, que esta tradição se erigiu com mais fecundidade.

No poema 754 podemos verificar a passagem à consciência do sujeito lírico à medida que abandona sua inércia/passividade original, se transforma em sujeito da voz e da ação e, em seguida, chama para si, na última estrofe, uma reflexão profunda sobre

\footnotetext{
${ }^{6}$ Escritora sulista norte-americana (1850-1904), autora de romances e contos que hoje são considerados fundamentais na formação de uma consciência literária feminina nos Estados Unidos, cuja obra reflete uma consciência aguda sobre a posição da mulher na sociedade patriarcal norte-americana do século XIX.
} 
o estatuto da arte e da vida que o levará a um grau de consciência em que confluem a liberdade e a responsabilidade extremas.

A última estrofe do poema traz uma conclusão surpreendente, na medida em que as reflexões ali presentes, ao invés de fechar o poema, abrem-no para múltiplas perspectivas interpretativas, como é comum acontecer na poesia de Emily Dickinson, mas estas possibilidades só se revelam a uma leitura contextualizada do poema, uma leitura que acompanhe a evolução do sujeito lírico até o momento final do poema, no qual uma conclusão sobre este processo se torna inevitável.

O primeiro dístico desta última estrofe ("Though I than $\mathrm{He}$ - may longer live / He longer must - than I") parece afirmar que é o sujeito lírico feminino que viverá mais do que o personagem masculino, não somente pela força e auto-afirmação poética que adquiriu em sua trajetória poética, mas sobretudo pela percepção de que a escrita é uma arma mais poderosa que a força e que, portanto, sua existência poética lhe garantirá uma vida muito mais longa que a vida mortal do personagem masculino. Neste ponto podemos perceber a articulação de uma consciência histórica com a voz lírica do poema, reafirmando o que dissemos anteriormente, i. e., que a voz lírica não é reflexo somente da consciência histórica da mulher escritora, mas é uma maneira de a mulher escritora adquirir sua consciência histórica, esvaziando o antigo debate sobre a ascendência da vida sobre a arte e vice-e-versa. Que Emily Dickinson tinha alguma consciência de que a relação entre a consciência histórica e o eu-lírico não são imediatas ou irrefletidas, podemos ver em uma de suas cartas (L 268) que fala de sua poesia: “Quando eu me pronuncio [isto é, quando uso "eu”] como um Representante do Verso não quer dizer eu - mas uma suposta pessoa" (DICKINSON apud JUHASZ e MILLER, 2002, p.109; ênfase e tradução minhas). Como afirmam ainda estas scholars da poesia de Dickinson,

[...] a construção de uma voz lírica aparentemente sincera ou autêntica é ainda uma construção. Não é a ralação do 'eu' com o poeta ou qualquer outra 'pessoa', mas o uso das palavras no contexto do discurso que implica em uma perspectiva ou subjetividade de alguma forma. (JUHASZ e MILLER, 2002, p.109). 
Mas a conquista da consciência não se dá, no caso da autoria feminina, sem um preço muito alto, que é vivido pelas autoras na forma de uma dupla ansiedade geradora de um forte sentimento de culpa, que nas escritoras do século XIX não somente foi o responsável pela criação de personagens femininas esquizofrênicas, doentes, loucas, mas também por vários tipos de doenças de mulheres associadas à cultura repressiva patriarcal, como afirmam Gubar e Gilbert (2000, p.53): "E, de fato, tais doenças de desajuste ao ambiente físico e social [do patriarcado], tais como anorexia e agorafobia afetaram e afetam um número desproporcional de mulheres."

Citamos, na íntegra, outro poema de Dickinson (Poema 1176) que nos ajudará a entender como este sentimento de culpa pela autoria feminina é trazido para o poema e tematizado como uma culpa coletiva com a qual as mulheres poetas têm que se haver no processo de criação (DICKINSON apud BRADLEY, 1974, p.1034-1035):

\footnotetext{
We never know how high we are

Till we are called to rise;

And then, if we are true to plan,

Our statures touch the skies-

The Heroism we recite

Would be a daily thing,

Did not ourselves the Cubits warp

For fear to be a King-
}

Mesmo com o medo de ser rei, o eu-lírico feminino, por meio do uso dos verbos modais no poema 754 , coloca a difícil questão de que embora o personagem masculino (metonímia da tradição), deva viver mais ("He longer must - than I" - minha ênfase), é o sujeito lírico feminino que provavelmente terá maior longevidade ("Though I than He - may longer live" - minha ênfase). Digo que é uma difícil questão, pois implica em dois níveis de leitura: o simbólico/irônico e o metapoético.

No nível simbólico de leitura deste dístico, percebemos que enquanto uma mão escreve o mea culpa da autoria feminina (o uso do verbo modal "must" indicando um dever, uma obrigação), reiterando os valores da tradição e afirmando que o homem deve 
viver mais, pois é dele que tudo emana, a outra mão hesitantemente (o uso do verbo modal "may", indicando uma possibilidade) indica que a sua existência (do eu-lírico) já não é uma existência à parte de todo o resto, uma exceção como no poema de Bradstreet, mas parte de um todo em movimento, uma tradição que se constrói a cada gesto de escrita, a cada tomada de consciência que a pena possibilita. Adentrar a cultura ocidental como sujeito, uma cultura que se distingue das outras culturas por ser uma cultura letrada, pode ser "um peso exagerado de sabedoria", um movimento que não pode apagar a história, que não pode simplesmente destituir os sentimentos duplos de prazer e culpa que a assunção da escrita traz consigo.

A ironia que se desenha - e que se completará no último dístico do poema - na verdade já vinha se revelando e crescendo desde o segundo dístico da segunda estrofe, quando o eu-lírico assume a fala no lugar do personagem masculino, mas neste momento a ironia atinge seu ápice no fato de que a voz poética feminina parece, como Davi diante do gigante Golias, dar o golpe de misericórdia e decretar o luto da tradição patriarcal, uma vez que o "I", como vimos, é uma persona poética carregada de traços autobiográficos, e o "He" é o personagem masculino silente que representa a tradição patriarcal. Neste ponto da leitura, a consciência adquirida pelo sujeito lírico da condição da poeta mulher numa sociedade patriarcal inevitavelmente nos leva (a nós, leitores) a uma identificação deste pronome da primeira pessoa do singular "I" com uma tradição literária feminina desejada e, até certo ponto existente e promissora à época de Dickinson, os anos 60 e 70 do século XIX, muito antes do movimento de liberação da mulher um século depois.

O nível metapoético de leitura se inicia no primeiro dístico da última estrofe, mas somente se concretiza com o dístico final, pela surpreendente revelação que faz o eu-lírico e que nos leva a nós, leitores, à dimensão do fazer poético e suas implicações para as pessoas e o mundo. É como se este eu-lírico repetisse o gesto poético de William Carlos Williams em seu conhecido poema "O carrinho de mão vermelho": "tanta coisa depende / de um // carrinho de mão / vermelho // esmaltado de água de / chuva // ao lado das galinhas / brancas" (1987, p.77). Assim como Williams usa a imagem do carrinho de mão vermelho para falar do poema e de sua importância no mundo, Dickinson revela que o poema é capaz de dar ao sujeito lírico uma força e uma 
existência sólidas, capazes de transformar o mundo "real", afetando-o de formas várias e duradouras.

Quando afirma este poder adquirido no poema, este eu-lírico feminino já se desembaraçou da dupla injunção da autoria poética feminina que constringiu a criação poética desde seu início no poema. Esta "queenly woman" que o eu-lírico feminino se torna, afirma - após a hesitação dos dois primeiros versos -, com firmeza e serenidade, ter o poder de matar ("For I have but the power to kill"), assumindo ainda mais completamente o papel do personagem masculino, pois a prerrogativa de matar é historicamente associada ao homem, seja na caça, na guerra ou na lei. Portanto, ter a força e a certeza de poder para matar implica, neste momento do poema e da consciência do eu-lírico feminino, na percepção de que o inimigo não é somente ou simplesmente o personagem masculino, mas toda a tradição patriarcal e a humanidade masculina, como diria a própria Dickinson no poema 528, numa atitude irônica em relação a esta arrogância e desejo de posse masculinos (DICKINSON apud BRADLEY, 1974, p.1029):

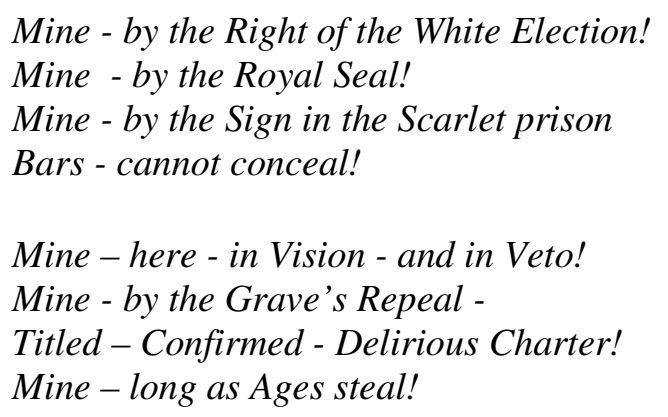

Invocando, neste último dístico, a dualidade matar/morrer, que poderia sugerir, mesmo que longinquamente, o tema centenário da guerra dos sexos, o sujeito lírico afirma primeiramente que tem o poder de matar para, em seguida, completar que não tem, entretanto, o poder de morrer ("Without--the power to die"), o que nos leva a pensar qual seria este poder infinitamente maior que o poder masculino de tirar a vida e, também, maior que o poder - feminino, por natureza - de dar a vida.

Uma primeira chave para a resposta a esta indagação pode ser simbólicoreligiosa e nos levaria à associação do eu-lírico feminino com Deus, o único que tem o 
poder de matar mas não de morrer, associação esta que poderia ser respaldada pela constância do motivo religioso na poesia de Dickinson, tendo a poeta recebido uma formação calvinista. Porém, nos vários poemas em que fala de Deus, a referência é feita sempre de forma oblíqua, às vezes até com uma certa ironia de quem desconfia do céu e das promessas para o além-vida, o que confere, certamente, um tom "existencialista" à sua poesia, como explica Fred D. White (2002, p.91; tradução minha):

É sempre tentador ver Dickinson como uma poeta confessional cujos poemas, por seu brilhantismo inovador, são ainda assim efusões de seus sentimentos particulares em relação ao amor, à morte, à natureza e à imortalidade. Entretanto, um olhar mais atento ao seu vasto projeto poético revela um objetivo artístico mais complexo, que se delicia tanto com as possibilidades quanto com as impossibilidades da língua em evocar as experiências da vida e da mente.

Sua relação com Deus e com o céu é de desconfiança, de repulsa até, pois a imortalidade (um dos temas recorrentes em sua poesia) que o eu-lírico busca é menos a imortalidade cristã da alma do que a imortalidade escritural da poeta e de seus versos. Citamos apenas a estrofe final do poema 324, no qual esta atitude em relação a Deus e ao céu é exposta (1974, p.1026): “God preaches, a noted Clergyman - / And the sermon is never long, / So instead of getting to Heaven, at last - / I'm going, all along."

Se o eu-lírico tem, portanto, o poder de matar mas não de morrer e se ele não é Deus tampouco, o desfecho do poema aponta para a dimensão poética como resolução do conflito entre a mortalidade e a imortalidade. Por um lado, a mortalidade da vida passageira, as glórias e o poder da tradição masculina; por outro, a imortalidade da poesia, que permite à poeta viver, subverter e recriar o mundo, pois como já foi dito, na poesia de Dickinson

[...] vemos a culminação deste processo, uma absorção quase completa dos personagens da ficção na persona de sua autora, de tal forma que esta autora e sua(s) protagonista(s) se tornam, para todos os efeitos práticos, uma - uma 'suposta pessoa' conquistando a 
autoridade da auto-criação ao interpretar várias identidades e vidas altamente literárias. (GUBAR e GILBERT, 2000, p.585).

Trata-se, portanto, de uma imortalidade garantida pela criação literária, possibilitando ao sujeito lírico o gesto violento de esmagar os inimigos como quem esmaga uma formiga com o polegar e, ao mesmo tempo, a afirmação serena de que só ele tem o poder da imortalidade. A poesia sobrevive à ação da história e das tradições e quando esta percepção acontece em uma poeta mulher o seu daimon instigador e provocador do mundo se acende, fazendo do sujeito lírico feminino um demiurgo às avessas, como Lilith, que queria a igualdade dos sexos, uma deusa poética que recria o mundo à sua imagem e semelhança.

A herança e a lição da poesia de Dickinson são tão valiosas e tão vastas que suas herdeiras estão por aí, fazendo poesia, (re)criando novos mundos e ironizando o desejo de poder masculino. Terminamos com alguns versos de uma das mais importantes herdeiras de Emily Dickinson na poesia norte-americana do século XX, Sylvia Plath, retirados de seu poema “Lady Lazarus" (1981, p.245-246):

Herr God, Herr Lucifer

Beware

Beware.

Out of the ash

I rise with my red hair

And I eat men like air. 


\section{REFERÊNCIAS}

BEAUVOIR, S. de. O segundo sexo: fatos e mitos. São Paulo: Difusão Europeia do Livro, 1970 (Vol. I).

BLOOM, H. A angústia da influência: uma teoria da poesia. Rio de Janeiro: Imago, 1991 (Biblioteca Pierre Menard).

BRADLEY, S. The American tradition in literature. New York: Grosset \& Dunlap, 1974.

CAMPOS, A. de. O anticrítico. São Paulo: Companhia das Letras, 1986.

CHOPIN, K. The awakening. New York: Dover, 1993.

CIXOUS, H. Sorties: Out and Out: Attacks/Ways Out/Forays. In: CIXOUS, H.; CLÉMENT, C. The newly born woman. Minnesota: University of Minnesota Press, 2001. p.63-132.

DERRIDA, J. The politics of friendship. New York: Verso, 2005.

ELIOT, T. S. Tradição e talento individual. In: Ensaios. São Paulo: Art Editora, 1989. p.37-48.

GUBAR, S. M.; GILBERT, S. The madwoman in the Attic: the woman writer and the nineteenth-century literary imagination. $2^{\text {nd }}$. Edition. New Haven: Yale University Press, 2000.

HEIDEGGER, M. Poetry, Language, Thought. New York: Harper Colophon Books, 1971.

JUHASZ, S.; MILLER, C. Performances of gender in Dickinson's poetry. In:

MARTIN, W. (Ed.). The Cambridge companion to Emily Dickinson. Cambridge:

Cambridge University Press, 2002. p.107-128.

PAGLIA, C. Personas sexuais: arte e decadência de Nefertite a Emily Dickinson. São Paulo: Companhia das Letras, 1992.

PLATH, S. The collected poems. New York: Buccaneer Books, 1981.

PRADO, A. Bagagem. Rio de Janeiro: Record, 2007.

WHITE, F. D. Emily Dickinson's existential dramas. In: MARTIN, W. (Ed.) The

Cambridge companion to Emily Dickinson. Cambridge: Cambridge University Press, 2002. p.91-106.

WILLIAMS, W. C. Poemas. São Paulo: Companhia das Letras, 1987.

WOOLF, V. Um teto todo seu. São Paulo: Círculo do Livro, s/d.

http://www.ibilce.unesp.br/departamentos/lem/emilydickinsoninbrazil/

http://www.lunaeamigos.com.br/fragrancia/emilydickinson.htm 
Artigo recebido em 23/08/2010

Aceito para publicação em 30/10/2010 